\title{
Recent advances in surgical treatment of hepatocellular carcinoma
}

\author{
Tianqiang Song* \\ Department of Hepatobiliary Tumors, Tianjin Medical University Cancer Institute and Hospital, Tianjin, China.
}

\begin{abstract}
Summary Hepatocellular carcinoma $(\mathrm{HCC})$ is a common and lethal malignancy worldwide that arises within the context of a host of diseases. Surgery is the primary option for tumor treatment and is thus the most effective therapy to allow the best overall survival and recurrence-free survival for patients. One aim of this paper is to present and discuss recent advances in the surgical treatment of HCC such as associating liver partition and portal vein ligation for staged hepatectomy (ALPPS), laparoscopic hepatectomy, and robotic liver resection, and another aim of this paper is to highlight current issues in the surgical treatment of $\mathrm{HCC}$ such as extended indications.
\end{abstract}

Keywords: Hepatocellular carcinoma, liver resection, laparoscopic hepatectomy, robotic, ALPPS, extended indications

\section{Introduction}

Hepatocellular carcinoma (HCC) is the sixth most common cancer and the second most common cause of cancer death; HCC is also the most common primary malignancy of the liver (1). The incidence of HCC is highest in East and Southeast Asia because of the prevalence of chronic hepatitis B in these regions. Standard potentially curative treatments for this cancer are either resection or transplantation, although radiofrequency ablation is considered a curative therapy in some cases (2). Better assessment of liver function, understanding of the segmental liver anatomy with more accurate imaging studies, and advances in surgical techniques are key factors that have led to a mortality rate of $<1 \%$ with an expected 5 -year survival rate of $70 \%(3-6)$. One aim of the current paper is to present and discuss recent advances in the surgical treatment of HCC, and another aim of this paper is to highlight current issues in the surgical treatment of HCC.

\section{Anatomical vs. non-anatomical resection}

Hepatic resection and radiofrequency ablation are

*Address correspondence to:

Dr. Tianqiang Song, Department of Hepatobiliary Tumors, Tianjin Medical University Cancer Institute and Hospital, Huanhuxi Road, Tiyuanbei, Hexi District, Tianjin 300060, China.

E-mail: tjchi@hotmail.com potentially curative treatments for HCC (7). Even after resection with curative intent, however, $\mathrm{HCC}$ has a high rate of recurrence, ranging from about $50 \%$ during the first 3 years after surgery to more than $70 \%$ during the first 5 years $(8-10)$. The high incidence of HCC recurrence may be explained by the high incidence of both intrahepatic metastases and the multicentric occurrence of de novo HCC (8). In the past, portal vein dissemination was considered to be the main route for intrahepatic metastases, which led to the notion that anatomical resection, the site of which is based on where the blood flow to a tumor drains into the portal vein, might prevent the development of intrahepatic metastases of HCC $(11,12)$. Data from a nationwide study in Japan (13) that included 5,781 patients with single HCCs revealed that anatomical subsegmentectomy (AS) was preferred over nonanatomical minor hepatectomy $(\mathrm{MH}) \mathrm{AS}$, especially when the size of the HCC ranged from 2 to $5 \mathrm{~cm}$. Overall disease-free survival (DFS) was significantly better after an AS ( $p=0.0089)$. If the HCC is smaller in size, one could reasonably deduce that there would be no statistical difference in the DFS after AS or $\mathrm{MH}$ since the risk of dissemination is presumably negligible, which means that both techniques had efficacy equivalent to that of local ablative therapy. If the HCC is larger, most patients will already have macroscopic vascular invasion or satellite nodules that will result in a high incidence of recurrence (14). This means a more advanced stage of HCC and evidence 
of the oncological behavior of the $\mathrm{HCC}$, potentially offsetting the effects of the technique used. $\mathrm{MH}$ is comparable to AS. Therefore, AS is a strong prognostic factor, especially for HCCs measuring from 2 to $5 \mathrm{~cm}$ in size. In the cited study, there were no significant differences when the patients who underwent AS or $\mathrm{MH}$ were further stratified depending on the degree of liver damage (which is similar to the Child-Pugh score). This was true even in patients with HCCs of 2 to $5 \mathrm{~cm}$ in diameter. Therefore, AS is recommended particularly when the $\mathrm{HCC}$ ranges from 2 to $5 \mathrm{~cm}$ in diameter. However, MH is an option for treatment of a single HCC if AS cannot be safely performed.

Ishii et al. (15) analyzed 268 consecutive patients with HCC, including 110 patients who underwent anatomic liver resection (AR) and 158 who underwent non-anatomic liver resection (NAR). Forty-four patients from each group were selected and matched using logistic multivariate analysis followed by propensity score analysis. AR conveyed a survival advantage over NAR in specific subpopulations of patients with an HCC less than $5 \mathrm{~cm}$ in diameter, a single tumor, and good liver function.

Kamiyama et al. (16) analyzed 322 consecutive patients with HCC who met the Milan criteria and who underwent curative resection (R0). Patients were classified into two groups: Group A (patients with a single HCC having a diameter of $5 \mathrm{~cm}$ or less) and Group B (patients with multiple tumors, no more than three tumor nodules, each with a diameter of $3 \mathrm{~cm}$ or less). Kamiyama et al. found that anatomical resection improved surgical outcomes for patients with HCC that met the Milan criteria.

Yamamoto et al. (17) analyzed 174 patients with a single $\mathrm{HCC} 2-5 \mathrm{~cm}$ in diameter and without macroscopic vascular invasion. Studies investigating the survival benefits of AR compared to NAR have yielded results that are not completely consistent. Yamamoto et al. recommended that patients with an ICGR $15<20 \%$ and poor liver function undergo NAR rather than AR for the treatment of a solitary HCC 2-5 $\mathrm{cm}$ in diameter.

Marubashi et al. (18) investigated the pattern of HCC recurrence to evaluate whether non-anatomical resection, which is based on where the blood supply to a tumor drains, and anatomical resection, which restricts resection to the corresponding site where the tumor's blood supply drains into the portal vein, was more beneficial. Local dissemination as a pattern of HCC recurrence was observed in only $6(1.4 \%)$ of the 424 patients included in their analysis. In the remaining patients, HCC recurrence was considered to be result of either systemic dissemination or de novo development of HCC. This "local dissemination" is a rather rare pattern of $\mathrm{HCC}$ recurrence, indicating that anatomical and non-anatomical resection are equally curative and that the selected technique did not influence patient outcomes. In other words, recurrence as a result of local dissemination can be ignored with both anatomical and non-anatomical resection. HCC recurring after curative resection is mostly caused by systemic dissemination of circulating tumor cells or de novo development of HCC.

In accordance with recent concepts and based on the evidence of HCC recurrence in patients with HCC who have undergone hepatic resection and liver transplantation, intrahepatic metastasis occurs because of the blood flow to a tumor or an aggregation of tumor cells in the remaining liver $(8,14,19)$. Some studies $(20$ 22) have demonstrated the superiority of anatomical resection over non-anatomical resection for treatment of HCC. Others (23-25) have questioned the validity of this suggestion, as they found no differences in $\mathrm{HCC}$ recurrence or overall survival rates for patients undergoing either form of resection after resection with curative intent. However, most reported studies had limited statistical power, and no case-matched or randomized clinical trials have compared the outcomes of anatomical and non-anatomical resection for treatment of HCC.

Clear evidence of the superiority of one technique over the other is not available since some studies have attributed a survival benefit to $\operatorname{AR}(26,27)$ while others have not $(28,29)$. Two recent meta-analyses of observational studies have also reported conflicting results $(30,31)$. Importantly, underlying cirrhosis was significantly more common in patients who underwent NAR and who also displayed greater hepatic dysfunction compared to patients who underwent AR. A meta-regression approach recently found that these aspects significantly affect the results of metaanalyses; that is, patient survival and DFS after AR seem to be superior to those after NAR because patients undergoing NAR have worse liver function reserve, which significantly affects prognosis (32).

Moreover, a recent meta-regression analysis was performed after adjusting for several key covariates, but results precluded the ready comparison of available studies on AR and NAR (33).

Thus, large randomized controlled trials are needed to define the best form of resection for patients with HCC developing from a cirrhotic liver (32).

\section{Associating liver partition and PVL for staged hepatectomy (ALPPS)}

Over the past few decades, advances in surgery, anesthesia, radiology, and oncology have resulted in an extension of the criteria for resectability of liver neoplasms $(34,35)$, but a small volume of the future liver remnant (FLR) has been the Achilles heel limiting major hepatectomy $(36,37)$. In general, most patients with HCC have an underlying liver disease, such as cirrhosis, that requires an FLR of at least $40 \%$ (38). Thus, surgeons 
face the challenge of choosing either resection of the hepatic tumor with a potential risk of postoperative liver failure (PHLF) or giving the patient palliative treatment, such as transcatheter arterial chemoembolization or local ablative therapy, to avoid PHLF if the volume of the FLR is on the borderline $(39,40)$. In recent years, some strategies, such as portal vein ligation (PVL), portal vein embolization (PVE), and two-stage liver resection have been developed to induce hypertrophy of the FLR prior to hepatectomy in primarily non-resectable liver tumors (41). Makuuchi et al. (42) first introduced the concept of PVE into clinical practice in the 1980s. In 2008, a metaanalysis of 37 studies conducted from 1990 to 2005 and involving 1088 patients revealed that 29 days, on average, elapsed from PVE to surgery, with an $8 \%$ to $27 \%$ increase in the FLR; in $14 \%$ of patients, resection was precluded after PVE due to disease progression or insufficient hypertrophy of the FLR (43). A systematic review and meta-analysis (44) compared PVL and PVE to assess the percentage increase in the FLR, morbidity, mortality, and tumor progression. All of the analyzed studies were retrospective. The 7 studies involved 218 patients, of whom 89 underwent PVL and of whom 129 underwent PVE. This meta-analysis comparing periprocedural outcomes of PVL and PVE revealed that the mean percentage increase in the FLR was 39\% with PVE and $27 \%$ with PVL, but the difference in the percent increase was not significant. In addition, the two techniques resulted in similar morbidity and mortality rates after liver resection, a similar time to hepatectomy, and a similar time to disease progression. The two-stage hepatectomy was pioneered by surgeons at the Hôpital Paul Brousse in the 2000s. The procedure was designed when removal of all malignant lesions in the liver was not possible using a single procedure (45). The first hepatectomy was intended to keep the final FLR clear of all malignant lesions. During the wait prior to the second surgery, hypertrophy of the FLR was induced to make the second hepatectomy feasible and potentially curative (46). However, the major reason for failure of the twostage hepatectomy was tumor progression while waiting for hypertrophy of the FLR or an insufficient increase in volume after portal vein occlusion $(47,48)$. In a recent review analyzing short- and long-term outcomes of a large series of two-stage hepatectomies, morbidity was reported to range between 20 and $60 \%$ after the second surgery and the drop-out rate was reported to range between 8 and $31 \%$ (49).

ALPPS is a new 2-stage surgical strategy to increase the size of FLR, but the procedure was invented by chance. Professor Hans Schlitt from Regensburg, Germany first performed ALPPS in 2007. He planned to perform an extended right hepatectomy in a patient with hilar cholangiocarcinoma. During surgery, he realized that the FLR was too small to sustain the patient's life postoperatively. Hence, he made a good but unusual surgical decision to perform only a selective left hepaticojejunostomy for palliation. For optimal positioning of the hepaticojejunostomy, he divided the liver parenchyma along the falciform ligament, thereby completely devascularizing segment 4. He also ligated the right portal vein in order to induce hypertrophy of the left lateral section of the liver. Out of curiosity, he performed a computed tomography scan on day 8 postoperatively. To his surprise, the left lateral section had massively grown in size. He successfully removed the diseased liver with a second surgery. This novel approach was formally reported as a series of 3 cases in a presentation by Baumgart et al. (50), from Mainz, Germany, during the Ninth E-AHPBA Meeting in Cape Town, South Africa in April 2011. In 2012, de Santibanes and Clavien (51) proposed the acronym "ALPPS" for this novel technique. PVL and PVE are traditional approaches to induce hypertrophy of the FLR prior to hepatectomy in primarily nonresectable liver tumors. However, these approaches fail in about $14 \%$ of patients. Adequate hypertrophy of the FLR using PVL or PVE generally takes more than four weeks. ALPPS can induce rapid growth of the FLR, which is greater than that of reported with portal vein embolization or occlusion alone. Recent studies have noted the marked hypertrophy of the FLR, which enlarges by $40-80 \%$ within 6-9 days. Faster hepatocyte regeneration has resulted in a lower drop-out rate for the two-stage procedure. This waiting time can be critical, especially for patients with marginally resectable tumors or oncologically aggressive tumors (52).

The indications for ALPPS include an FLR of less than $30 \%$ in patients with a normal liver or an FLR of less than $40 \%$ in patients with a diseased liver caused by cholestasis, macrosteatosis, fibrosis, or pathologic changes associated with chemotherapy. Indications include marginally resectable or locally advanced unresectable liver tumors of any origin with an insufficient FLR either in terms of volume or quality. The pathologies that ALPPS is commonly used to treat include colorectal liver metastases, hilar cholangiocarcinoma, and HCC. Contraindications for ALPPS include unresectable liver metastases in the FLR, unresectable extrahepatic metastases, severe portal hypertension, high anesthetic risks, and a poor condition prior to major surgery (53).

In the beginning, ALPPS was mostly used to treat metastatic liver diseases. A liver with an underlying disease is known to have a lower capacity for regeneration and hypertrophy. In fact, a cirrhotic liver is less capable for hypertrophy after PVE than is a healthy liver. Vennarecci et al. (54) found that $i$ ) the ALLPS procedure is technically feasible and safe even when performing a major liver resection to treat HCC in a cirrhotic liver, that $i i)$ the procedure is able to induce a significant increase in the volume of the FLR in a short period of time, allowing completion of the second stage of ALPPS, and that iii) the volume of 
the FLR continues to increase even in a cirrhotic liver after the hepatectomy. Oncological results and short and long-term survival times of patients with a large HCC and major vascular invasion treated with ALPPS are not yet available. Now that the initial experimental phase has passed, prospective controlled studies with large samples are needed to properly evaluate ALPSS. An FLR to BWR ratio of at least $0.5 \%$ in a normal liver and a ratio of $0.8 \%$ in a cirrhotic liver should be achieved in order to avoid the considerable risk of hepatic decompensation and postoperative mortality.

ALPPS was reported to have high rates of operative morbidity, mortality, and bile leakage. Morbidity after ALPPS is reported to be $16 \%-64 \%$, and mortality is reported to be $12-23 \%$. The main forms of morbidity included bile leakage and sepsis, and the main cause of mortality was hepatic insufficiency. Total laparoscopic ALPPS has been reported $(55,56)$ to cause fewer adhesions during the second stage of surgery. The longterm oncological outcomes following ALPPS are not yet available, but the 5-year overall survival rate after a standard two-stage hepatectomy is reported to be $51 \%$. However, more studies are needed to evaluate the role of ALPPS in patients with hepatic fibrosis.

ALPPS has emerged as a new strategy to increase the resectability of hepatic malignancies. Due to the high morbidity and mortality rates of ALPPS, surgical candidates should be carefully selected. Moreover, there is very limited evidence of the technical feasibility, safety, and oncological outcomes of this procedure, so these aspects need to be evaluated further in large-scale studies.

\section{Indications for and the current role of laparoscopy}

Although laparoscopic surgery has been widely used in the field of abdominal surgery, such as colon and gastric surgery, use of laparoscopic liver resection is still limited to specialized facilities. Laparoscopic liver resection requires sufficient experience in both laparoscopic and open surgery. In addition, it requires advanced laparoscopic surgical techniques associated with parenchymal dissection and hemostasis. Laparoscopic liver resection has been used to treat various liver diseases as experience with laparoscopic surgery has increased and laparoscopic instruments have been developed (57).

Laparoscopic resection to treat $\mathrm{HCC}$ was first performed in 1992 (58). Initially, laparoscopic liver resection was only used to treat lesions located in the left lateral or peripheral segments. Due to the difficulty of controlling bleeding and visualization of the surgical field, lesions in the deep or posterior sections of the liver (segments I, VII, and VIII and the superior part of IV) were previously considered to be unsuitable for laparoscopic liver resection $(59,60)$. A group of experts met in Louisville, Kentucky, United States in 2008 and determined that the best indications for laparoscopy were solitary lesions, less than $5 \mathrm{~cm}$ in diameter, located in the anterior segments at a distance from the line of transection, the hepatic hilum, and the vena cava (61). Since that time, surgical indications have continued to evolve: tumor size alone is no longer a contraindication for laparoscopic surgery (62) and experienced facilities use laparoscopic resection to treat tumors in the posterior segments or center of the liver $(63,64)$.

Obtaining a safe margin for the inferior portion of a tumor is difficult when the tumor is located in the posterior or superior part of the liver. However, recent studies have noted the feasibility and safety of laparoscopic liver resection of lesions in those locations (65,66). Since Azagra et al. (67) performed the first anatomical resection, laparoscopic left lateral sectionectomy has become the standard treatment at some facilities (68). According to one study (57), laparoscopic left lateral sectionectomy was the most common form of anatomical liver resection. In the future, though, laparoscopic left lateral sectionectomy may become a routine procedure at most facilities. However, laparoscopic major hepatectomy is not used worldwide because of the complexity of the procedure and the fear of causing uncontrollable bleeding. This procedure should be performed by an experienced surgeon according to an expert consensus on laparoscopic liver surgery (69).

Laparoscopic resection is associated with significantly less intraoperative blood loss and less need for transfused blood, which can partly be explained by the hemostatic effect of pneumoperitoneum (70) and the magnified vision afforded by laparoscopy $(70,71)$. In addition, transfusion rates have been identified as an independent prognostic factor for DFS in $\operatorname{HCC}(72,73)$, and blood loss was found to be independently associated with recurrence and decreased survival rates after resection of HCC (74). Laparoscopy should reduce the need for a transfusion and thus improve the prognosis for patients undergoing a resection to treat $\mathrm{HCC}$ (75).

A recent meta-analysis by Yin et al. (76) found that the postoperative morbidity rate after laparoscopic resection of HCC decreased significantly in comparison to open surgery. A meta-analysis indicated that laparoscopic resection consistently yields favorable results in terms of the duration of hospitalization (7779 ), consequently reducing the overall morbidity rate and incidence of intractable ascites. The main concern about using laparoscopy to treat malignancies is the risk of inadequate tumor resection. In a number of studies (76-79) comparing laparoscopic and open liver resection for treatment of $\mathrm{HCC}$, there was no significant difference in recurrence-free or overall survival, suggesting that laparoscopic surgery does not compromise oncological principles.

Nonetheless, some studies have criticized laparoscopic resection because of its low level of 
reproducibility and because it is limited to a few specialized facilities. After a learning curve of 60 procedures $(80)$, there is significant improvement in terms of operating time, conversion rate, blood loss, morbidity, and duration of hospitalization. This suggests that laparoscopic resection is reproducible at facilities regularly performing liver surgery but that it requires specific training in advanced laparoscopy.

Laparoscopic liver resection is a new strategy for liver surgery that is needed to treat liver tumors.

\section{Robotic liver resection}

Hepatobiliary (HB) surgery is a challenging surgical subspecialty that requires highly specialized training and an adequate level of experience in order to be performed safely. Although the technical feasibility of a laparoscopic approach has been extensively demonstrated, its use has not extended to the broader community of surgeons performing HB surgery. This is due in large part to the limitations of the procedure, since it can be safely performed by a few highly experienced surgeons. Recent development of robotic platforms has provided a tool that can overcome many of the limitations of conventional laparoscopic HB surgery. Augmented dexterity enabled by endowristed movements, software filtration of the surgeon's movements, and high-definition three-dimensional vision provided by the stereoscopic camera combine to allow steady and careful dissection of the structures of the liver hilum as well as prompt and precise endosuturing in cases of intraoperative bleeding. These advantages have allowed many facilities to expand the indications for minimally invasive HB surgery, with encouraging initial results (81). In 2003, Giulianotti et al. (82) reported the first use of a robotic liver resection. The indications for robotic hepatectomy are similar to those for laparoscopic hepatectomy. Both benign and malignant tumors can be resected robotically. Laparoscopic hepatectomy for lesions in the superoposterior segments, such as segments VII and VIII, is particularly challenging due to their positions and the curved transection lines. As a result, lesions in these segments may be more commonly resected via a right hepatectomy, sacrificing a substantial volume of the normal liver (83). Robotic hepatectomy helps overcome this problem and some authors have reported success with this approach (84). Thus the greatest theoretical advantage of robotic hepatectomy may lie in sectoral, segmental, or subsegmental resection of lesions in difficult-to-reach positions. As a result, patients may be spared the large incisions and extensive mobilization required in an open approach.

The most prolific use of robotic hepatectomy to date was reported by Giulianotti et al. (85), who described procedures performed by a single surgeon in 70 cases (60\% malignant, $40 \%$ benign). Twenty-seven patients underwent a major hepatectomy; of those, 20 underwent right hepatectomy, 5 underwent left hepatectomy, and 2 underwent right trisectionectomy. Few studies have compared robotic to laparoscopic liver resection. Berber et al. found that the operating time, blood loss, and resection margins differed (86). Ji et al. found that robotic resection may involve a longer operating time than laparoscopic or open resection but comparable blood loss and complications (87). Lai et al. found a similar association in patients undergoing minor hepatectomy (< 3 segments) alone (88). The largest matched comparison of laparoscopic and robotic hepatectomy was reported by Tsung et al. and the University of Pittsburgh group (89). In this retrospective study, 57 patients undergoing robotic hepatectomy were matched with 114 patients undergoing laparoscopic hepatectomy based on underlying liver disease, the extent of resection, the diagnosis, ASA class, age, BMI, and gender. They found that the operating time was significantly longer for both major and minor hepatectomies that were performed robotically. There were no significant differences in complication rates, length of stay, mortality, and negative margin rates. A systematic review (90) identified 232 unique patients. Overall, the outcomes reported were similar to those seen in large laparoscopic series, but there was no clear difference in the outcomes of a robotic or laparoscopic approach. The key issue is to define the best indications for robotic liver resection. Despite the subjective advantages of a robotic system (maneuverability, ergonomics, and 3D vision), identifying its objective advantages is difficult in light of the current literature. Some authors have found that robotic technology provides an advantage mainly in two key steps during hepatectomy: dissection of the hilum and the hepatocaval dissection in the event of a right hepatectomy (88). In addition, the microsuturing capacity of a robotic system allows reconstruction of the biliary anatomy (91).

Overall, robotic technology has developed and it has expanded the indications for minimally invasive surgery. This technology might facilitate the treatment of large lesions and lesions that are posteriorly located.

The crucial point for a new technology is to offer advantages without sacrificing safety. With minimally invasive surgery, surgical stress is reduced, whether it is by a robotic or a laparoscopic approach. Like laparoscopy $(92,93)$, a robotic approach yields results comparable to those of open surgery (94), primarily by minimizing blood loss and reducing the risk of a required transfusion (in the patients described). However, oncological outcomes rather than feasibility and peri-operative safety are the key to determining whether an approach is effective at treating malignancies; the same was true for laparoscopy several years ago (95). Even though only a limited number of patients were selected, the available data do not appear to indicate that oncological principles have been sacrificed. The reported outcomes compare favorably to those of a laparoscopic or open approach 
$(92,96)$ as indicated by a low rate of recurrence. A point worth noting is that the robotic approach has not been followed for a long enough period of time, so that approach needs to be examined in comparison to other approaches. Nevertheless, the robotic approach provides results, at 2 years for treatment of HCC (88) and at 3 years for treatment of colorectal metastasis (97), that are similar to those reported in systematic reviews of laparoscopic approaches (96). The increasing interest in robotic technology should help encourage randomized studies with larger samples and a longer follow-up. With quality evidence, the robotic approach might become the minimally invasive treatment of choice in advanced and complex cases.

One of the major disadvantages of robotic surgery is the high cost. In a systematic review of the literature in English, Turchetti et al. analyzed 11 studies that compared the cost of robotic surgery to that of a laparoscopic approach in various abdominal surgeries. The cost of the robotic approach was generally higher due to the longer operating time (and especially the setup time) and instruments required, although the costs of hospitalization were similar (98). The purchase and maintenance costs are significant, particularly for lowervolume facilities, but many studies have not included these costs.

Robotic liver resection is safe and feasible when performed by an experienced surgeon. The procedure requires an expert patient-side surgeon with advanced laparoscopic skills. Wristed instruments are useful in a variety of maneuvers, such as looping Glissonian pedicles (especially on the left side of the liver) and in suturing bleeding points. The learning curve for robotic resection may be shorter than that of conventional laparoscopic liver surgery because the three dimensional imaging camera, wristed instruments, and better ergonomics will help experienced laparoscopic surgeons to quickly familiarize themselves with the robotic procedure (99). Despite the limited number of cases reported in the literature $(85,87,88)$, the use of a robot to perform a minor or major liver resection appears to be a safe and feasible alternative to the open and laparoscopic approaches, resulting in lower postoperative morbidity and adequate oncological outcomes for primary and metastatic diseases. Most of the studies of robotic liver resection have focused on short-term perioperative outcomes (100). Long-term oncologic results and costeffectiveness must be evaluated before the advantages and disadvantages of robotic liver resection can be conclusively determined. Robotic HB surgery has been rapidly increasing over the past few years. A prospective comparative study should be conducted to verify the advantages of robotic liver resection for the management of HCC. The development of new technologies and robotics will certainly expand the use of laparoscopy in the multimodal management of hepatocarcinoma (101).

\section{Should indications for surgery be expanded beyond the BCLC criteria?}

Curative treatments, including liver transplantation, surgical resection, and percutaneous ablation, are able to achieve a long-term survival rate of more than $50 \%$ at 5 years; however, only a small group of patients with early-stage HCC are eligible for these therapies (102107). Most patients have advanced HCC when they are diagnosed. Thus, several HCC staging systems based on the tumor burden and liver function have been proposed over the past decades to guide therapeutic decisions (108-113). The Barcelona Clinic Liver Cancer (BCLC) staging system is accepted worldwide for clinical practice. The BCLC classification divides patients with $\mathrm{HCC}$ into 5 stages $(0, \mathrm{~A}, \mathrm{~B}, \mathrm{C}$, and $\mathrm{D})$ depending on tumor status-related variables (size, number, vascular invasion, $\mathrm{N} 1$, and $\mathrm{M} 1$ ), liver function (Child-Pugh grade), and health status (ECOG). The BCLC classification divides patients with HCC into stages depending on prognostic variables and allocates therapies depending on treatment-related status (114). For example, BCLC stage B is defined as an intermediate stage. Chemoembolization is recommended as the standard treatment of intermediatestage (BCLC stage B) HCC (114).

According to the BCLC classification, liver resection should be performed only in patients with a small single HCC nodule without signs of portal hypertension or hyperbilirubinemia. Based on the BCLC classification, patients with multiple $\mathrm{HCCs}$, a large $\mathrm{HCC}$, or HCC with macrovascular invasion should undergo palliative treatment with unsatisfactory long-term results even if the lesion is resectable (115-117). However, recent studies have reported that surgical resection can lead to good short- and long-term survival rates for these patients (118-121).

Therefore, this classification has been criticized because it excludes many patients who could benefit from curative resection (122-125). Use of liver resection in cases of multiple HCCs is still controversial $(126,127)$. According to the BCLC classification, all patients with multiple HCCs should be scheduled for percutaneous ablation or TACE if liver transplantation is contraindicated (125). Poon et al. (128) reported a 5 -year survival rate of $60 \%$ after liver resection in patients with fewer than $3 \mathrm{HCC}$ nodules $\leq 3 \mathrm{~cm}$. Ruzzenente et al. (121) conducted a study of 464 patients with HCC from a multi-institutional database and they found that patients with fewer than 3 nodules who underwent liver resection had a higher survival rate than those who were treated with local ablative therapies (including percutaneous ablation and TACE), as indicated by a median survival time of 58 months versus 20 months with local ablative therapies $(p<$ 0.01 ). These findings were verified by a subsequent randomized controlled trial. The authors reported that 
patients with multifocal HCC meeting the Milan criteria had a 5-year survival rate of $69 \%$ after liver resection and $45 \%$ after radiofrequency ablation $(p=0.042)(129)$. In selected patients with multinodular BCLC B (more than 3 nodules) HCC and preserved liver function, liver resection yielded better long-term results than TACE with a 5-year survival rate of $36-37 \%$ compared to 11 14\% with TACE (130). Although further studies need to verify these results, liver resection seems to offer satisfactory long-term results for patients with multiple HCCs. Macrovascular invasion (MVI) is one of the strongest predictors of survival in patients with HCC $(131,132)$. The median survival time for patients with untreated HCC and PVTT is 2.7 months while that for patients with untreated HCC and MVI is 5 months $(133,134)$. After sorafenib treatment, these patients are reported to have a survival time of 6 months (135). In recent series of surgical cases including MVI by HCC, the postoperative mortality rate ranged from $3.4 \%$ to $7.7 \%$ and the morbidity rate ranged from $30.8 \%$ to $37.1 \%(120,136,137)$. In a multicenter study of 102 patients with MVI by HCC who underwent surgical resection, Pawlik et al. reported that patients had a 5 -year survival rate of $10 \%$ (120). Better survival rates are reported for selected patients with PVTT, with a 5 -year survival rate ranging from $11 \%$ to $42 \%$ according to the literature (137-140). According to the Hong Kong Consensus Recommendations on the Management of Hepatocellular Carcinoma, resection may be considered in some patients with BCLC grade B or C liver disease, which the Consensus Recommendations classify as HKLC stage II. According to the Consensus Recommendations, resection of isolated extrahepatic metastasis after hepatic resection is justified in selected patients with HKLC stage II HCC (141). No meta-analyses have been performed, so the available evidence is limited.

Recent improvements in surgical techniques and perioperative care have enhanced the feasibility and safety of liver resection with satisfactory long-term results in selected patients with early $\mathrm{HCC}$ and $\mathrm{PH}$ and with intermediate-advanced HCC. Based on the BCLC algorithm, the EASL/AASLD guidelines currently exclude many patients from curative treatment even though they may benefit from liver resection. No other HCC classification has been recognized worldwide. Based on data in the literature, the treatment strategy should be tailored to the individual patient. Thus, the BCLC algorithm should be revised and clinical guidelines that possibly include new molecular classifications should be introduced (142).

\section{Conclusion}

The incidence of HCC has been increasing worldwide. HCC remains an aggressive malignancy that is one of the more common causes of cancer-related death.
Surgery is the primary option for tumor treatment and is thus the most effective therapy to allow the best overall survival and recurrence-free survival for patients. Surgery will gain further importance since there are emerging insights into the indications for liver resection to treat $\mathrm{HCC}$ indicating that these indications can be expanded to tumor stages outside of previous recommendations. This malignancy can be cured in appropriately selected patients through use of advanced surgical techniques. Newer imaging modalities continue to advance, surgical approaches are being devised, and patient selection is improving, so there are grounds for believing that the outcomes of HCC treatment will improve.

\section{References}

1. Torre LA1, Bray F, Siegel RL, Ferlay J, Lortet-Tieulent J, Jemal A. Global cancer statistics, 2012. CA Cancer J Clin. 2015; 65:87-108.

2. Lau WY, Lai EC. Hepatocellular carcinoma: Current management and recent advances. Hepatobiliary Pancreat Dis Int. 2008; 7:237-257.

3. Eguchi S, Kanematsu T, Arii S, Omata M, Kudo M, Sakamoto M, Takayasu K, Makuuchi M, Matsuyama Y, Monden M; Liver Cancer Study Group of Japan. Recurrence-free survival more than 10 years after liver resection for hepatocellular carcinoma. Br J Surg. 2011; 98:552-557.

4. Torzilli G, Makuuchi M, Inoue K, Takayama T, Sakamoto Y, Sugawara Y, Kubota K, Zucchi A. No-mortality liver resection for hepatocellular carcinoma in cirrhotic and noncirrhotic patients: Is there a way? A prospective analysis of our approach. Arch Surg. 1999; 134:984-992.

5. Andreou A, Vauthey JN, Cherqui D, Zimmitti G, Ribero D, Truty MJ, Wei SH, Curley SA, Laurent A, Poon RT, Belghiti J, Nagorney DM, Aloia TA; International Cooperative Study Group on Hepatocellular Carcinoma. Improved long-term survival after major resection for hepatocellular carcinoma: A multicenter analysis based on a new definition of major hepatectomy. J Gastrointest Surg. 2013; 17:66-77.

6. Imamura H, Seyama Y, Kokudo N, Maema A, Sugawara Y, Sano K, Takayama T, Makuuchi M. One thousand fifty six hepatectomies without mortality in 8 years. Arch Surg. 2003; 138:1198-1206; discussion 1206.

7. Tiong L, Maddern GJ. Systematic review and metaanalysis of survival and disease recurrence after radiofrequency ablation for hepatocellular carcinoma. $\mathrm{Br} \mathrm{J}$ Surg. 2011; 98:1210-1224.

8. Sakon M, Nagano H, Nakamori S, Dono K, Umeshita K, Murakami T, Nakamura H, Monden M. Intrahepatic recurrences of hepatocellular carcinoma after hepatectomy: Analysis based on tumor hemodynamics. Arch Surg. 2002; 137:94-99.

9. Belghiti J, Panis Y, Farges O, Benhamou JP, Fekete F. Intrahepatic recurrence after resection of hepatocellular carcinoma complicating cirrhosis. Ann Surg. 1991; 214:114-117.

10. Nagasue N, Uchida M, Makino Y, Takemoto Y, Yamanoi A, Hayashi T. Incidence and factors associated with intrahepatic recurrence following resection of 
hepatocellular carcinoma. Gastroenterology 1993; 105:488-494.

11. Sasaki K, Matsuda M, Ohkura Y, Hashimoto M, Watanabe G. Anatomical versus nonanatomical resection in patients with hepatocellular carcinoma located in the left lateral segment. Am Surg. 2013; 79:1163-1170.

12. Ochiai T, Ikoma H, Yamamoto Y, Konishi H, Murayama Y, Shiozaki A, Komatsu S, Kuriu Y, Kubota T, Nakanishi M, Ichikawa D, Fujiwara H, Okamoto K, Otsuji E. Anatomical hepatectomy for hepatocellular carcinoma in patients with preserved liver function. Anticancer Res. 2013; 33:1689-1695.

13. Eguchi S, Kanematsu T, Arii S, Okazaki M, Okita K, Omata M, Ikai I, Kudo M, Kojiro M, Makuuchi M, Monden M, Matsuyama Y, Nakanuma Y, Takayasu K. Comparison of the outcomes between an anatomical subsegmentectomy and a non-anatomical minor hepatectomy for single hepatocellular carcinomas based on a Japanese nationwide survey. Surgery. 2008; 143:469475.

14. Ueno S, Kubo F, Sakoda M, Hiwatashi K, Tateno T, Mataki Y, Maemura K, Shinchi H, Natsugoe S, Aikou T. Efficacy of anatomic resection $v s$ nonanatomic resection for small nodular hepatocellular carcinoma based on gross classification. J Hepatobiliary Pancreat Surg. 2008; 15:493-500.

15. Ishii M, Mizuguchi T, Kawamoto M, Meguro M, Ota S, Nishidate T, Okita K, Kimura Y, Hui TT, Hirata K. Propensity score analysis demonstrated the prognostic advantage of anatomical liver resection in hepatocellular Carcinoma World J Gastroenterol. 2014; 20:3335-3342.

16. Kamiyama T, Nakanishi K, Yokoo H, Kamachi H, Matsushita M, Todo S. The impact of anatomical resection for hepatocellular carcinoma that meets the Milan criteria. J Surg Oncol. 2010; 101:54-60.

17. Yamamoto Y, Ikoma H, Morimura R, Konishi H, Murayama Y, Komatsu S, Shiozaki A, Kuriu Y, Kubota T, Nakanishi M, Ichikawa D, Fujiwara H, Okamoto K, Sakakura C, Ochiai T, Otsuji E. Clinical analysis of anatomical resection for the treatment of hepatocellular carcinoma based on the stratification of liver function World J Surg. 2014; 38:1154-1163.

18. Marubashi S, Gotoh K, Akita H, et al. Analysis of recurrence patterns after anatomical or non-anatomical resection for hepatocellular carcinoma. Ann Surg Oncol. $2015 ; 22: 2243-2252$.

19. Sakon M, Ogawa H, Fujita M, Nagano H. Hepatic resection for hepatocellular carcinoma based on tumor hemodynamics. Hepatol Res. 2013; 43:155-164.

20. Wakai T, Shirai Y, Sakata J, Kaneko K, Cruz PV, Akazawa $\mathrm{K}$, Hatakeyama K. Anatomic resection independently improves long-term survival in patients with T1T2 hepatocellular carcinoma. Ann Surg Oncol. 2007; 14:1356-1365.

21. Ueno S, Kubo F, Sakoda M, Hiwatashi K, Tateno T, Mataki Y, Maemura K, Shinchi H, Natsugoe S, Aikou T. Efficacy of anatomic resection $v s$ nonanatomic resection for small nodular hepatocellular carcinoma based on gross classification. J Hepatobiliary Pancreat Surg. 2008; 15:493-500.

22. Zhou Y, Xu D, Wu L, Li B. Meta-analysis of anatomic resection versus nonanatomic resection for hepatocellular carcinoma. Langenbecks Arch Surg. 2011; 396:1109-1117.

23. Tanaka K, Shimada H, Matsumoto C, Matsuo K, Nagano Y, Endo I, Togo S. Anatomic versus limited nonanatomic resection for solitary hepatocellular carcinoma. Surgery. 2008; 143:607-615.

24. Kang CM, Choi GH, Kim DH, Choi SB, Kim KS, Choi JS, Lee WJ. Revisiting the role of nonanatomic resection of small $(<$ or $=4 \mathrm{~cm})$ and single hepatocellular carcinoma in patients with well-preserved liver function. J Surg Res. 2010; 160:81-89.

25. Tomimaru Y, Eguchi H, Marubashi S, Wada H, Kobayashi S, Tanemura M, Umeshita K, Doki Y, Mori M, Nagano H. Equivalent outcomes after anatomical and non-anatomical resection of small hepatocellular carcinoma in patients with preserved liver function. Dig Dis Sci. 2012; 57:19421948.

26. Yamashita Y, Taketomi A, Itoh S, Kitagawa D, Kayashima H, Harimoto N, Tsujita E, Kuroda Y, Maehara Y. Longterm favorable results of limited hepatic resections for patients with hepatocellular carcinoma: 20 years of experience. J Am Coll Surg. 2007; 205:19-26.

27. Regimbeau JM, Kianmanesh R, Farges O, Dondero F, Sauvanet A, Belghiti J. Extent of liver resection influences the outcome in patients with cirrhosis and small hepatocellular carcinoma. Surgery. 2002; 131:311-317.

28. Capussotti L, Muratore A, Amisano M, Polastri R, Bouzari H, Massucco P. Liver resection for hepatocellular carcinoma on cirrhosis: Analysis of mortality, morbidity and survival--A European single center experience. Eur J Surg Oncol. 2005; 31:986-993.

29. Kaibori M, Matsui Y, Hijikawa T, Uchida Y, Kwon AH, Kamiyama Y. Comparison of limited and anatomic hepatic resection for hepatocellular carcinoma with hepatitis C. Surgery 2006; 139:385-394.

30. Chen J, Huang K, Wu J, Zhu H, Shi Y, Wang Y, Zhao G. Survival after anatomic resection versus nonanatomic resection for hepatocellular carcinoma: A meta-analysis. Dig Dis Sci. 2011; 56:1626-1633.

31. Zhou Y, Xu D, Wu L, Li B. Meta-analysis of anatomic resection versus nonanatomic resection for hepatocellular carcinoma. Langenbecks Arch Surg. 2011; 396:1109-1117.

32. Cucchetti A, Cescon M, Ercolani G, Bigonzi E, Torzilli G, Pinna AD. A comprehensive meta-regression analysis on outcome of anatomic resection versus nonanatomic resection for hepatocellular carcinoma. Ann Surg Oncol. 2012; 19:3697-3705.

33. Cucchetti A, Cescon M, Ercolani G, et al. A comprehensive meta-regression analysis on outcome of anatomic resection versus nonanatomic resection for hepatocellular carcinoma. Ann Surg Oncol. 2012; 19:3697-3705.

34. Adam R, Wicherts DA, de Haas RJ, Ciacio O, Lévi F, Paule B, Ducreux M, Azoulay D, Bismuth H, Castaing D. Patients with initially unresectable colorectal liver metastases: Is there a possibility of cure? J Clin Oncol. 2009; 27:1829-1835.

35. Masi G, Cupini S, Marcucci L, Cerri E, Loupakis F, Allegrini G, Brunetti IM, Pfanner E, Viti M, Goletti O, Filipponi F, Falcone A. Treatment with 5-fluorouracil/ folinic acid, oxaliplatin, and irinotecan enables surgical resection of metastases in patients with initially unresectable metastatic colorectal cancer. Ann Surg Oncol. 2006; 13:58-65.

36. May BJ, Talenfeld AD, Madoff DC. Update on portal vein embolization: Evidence-based outcomes, controversies, and novel strategies. J Vasc Interv Radiol. 2013; 24:24154.

37. Azoulay D, Castaing D, Krissat J, Smail A, Hargreaves 
GM, Lemoine A, Emile JF, Bismuth H. Percutaneous portal vein embolization increases the feasibility and safety of major liver resection for hepatocellular carcinoma in injured liver. Ann Surg. 2000; 232:665-672.

38. Truant S, Oberlin O, Sergent G, Lebuffe G, Gambiez L, Ernst O, Pruvot FR. Remnant liver volume to body weight ratio $>$ or $0.5 \%$ : A new cut-off to estimate postoperative risks after extended resection in noncirrhotic liver. J Am Coll Surg. 2007; 204:22-33.

39. Adam R, Akpinar E, Johann M, Kunstlinger F, Majno $\mathrm{P}$, Bismuth $\mathrm{H}$. Place of cryosurgery in the treatment of malignant liver tumors. Ann Surg. 1997; 225:39-48 (discussion 48-50).

40. Wang ZJ, Wang MQ, Duan F, Song P, Liu FY, Chang ZF, Wang Y, Yan JY, Li K. Transcatheter arterial chemoembolization followed by immediate radiofrequency ablation for large solitary hepatocellular carcinomas, World J Gastroenterol. 2013; 19:4192-4199.

41. Zhang GQ, Zhang ZW, Lau WY, Chen XP. Associating liver partition and portal vein ligation for staged hepatectomy (ALPPS): A new strategy to increase resectability in liver surgery. Int J Surg. 2014; 12:437-441.

42. Makuuchi M, Thai BL, Takayasu K, Takayama T, Kosuge T, Gunvén P, Yamazaki S, Hasegawa H, Ozaki H. Preoperative portal embolization to increase safety of major hepatectomy for hilar bile duct carcinoma: A preliminary report. Surgery. 1990; 107:521-527.

43. Abulkhir A, Limongelli P, Healey AJ, Damrah O, Tait P, Jackson J, Habib N, Jiao LR. Preoperative portal vein embolization for major liver resection: A meta-analysis. Ann Surg. 2008; 247:49-57.

44. Pandanaboyana S1, Bell R, Hidalgo E, Toogood G, Prasad KR, Bartlett A, Lodge P. A systematic review and meta-analysis of portal vein ligation versus portal vein embolization for elective liver resection. Surgery. 2015; 157:690-698.

45. Adam R, Laurent A, Azoulay D, Castaing D, Bismuth H. Two-stage hepatectomy: A planned strategy to treat irresectable liver tumors. Ann Surg. 2000; 232:777-785.

46. Adam R, Miller R, Pitombo M, Wicherts DA, de Haas RJ, Bitsakou G, Aloia T. Two-stage hepatectomy approach for initially unresectable colorectal hepatic metastases. Surg Oncol Clin N Am. 2007; 16:525-536.

47. Brouquet A, Abdalla EK, Kopetz S, Garrett CR, Overman MJ, Eng C, Andreou A, Loyer EM, Madoff DC, Curley SA, Vauthey JN. High survival rate after twostage resection of advanced colorectal liver metastases: Response-based selection and complete resection define outcome. J Clin Oncol. 2011; 29:1083-1090.

48. Narita M, Oussoultzoglou E, Jaeck D, Fuchschuber P, Rosso E, Pessaux P, Marzano E, Bachellier P. Twostage hepatectomy for multiple bilobar colorectal liver metastases. Br J Surg. 2011; 98:1463-1475.

49. Lam VW, Laurence JM, Johnston E, Hollands MJ, Pleass HC, Richardson AJ. A systematic review of twostage hepatectomy in patients with initially unresectable colorectal liver metastases. HPB. 2013; 15:483-491.

50. Baumgart J, Lang SA, Goessmann H. A new method for induction of liver hypertrophy prior to right trisectionectomy: A report of three cases. HPB. 2011; 13 (Suppl. 2):1-145.

51. de Santibanes E, Clavien PA. Playing Play-Doh to prevent postoperative liver failure: The "ALPPS" approach. Ann Surg. 2012; 255:415-417.

52. Lau WY, Lau SH. Comments on associating liver partition and portal vein ligation for staged hepatectomy. Zhonghua Wei Chang Wai Ke Za Zhi. 2013; 12:481-484

53. Alvarez FA, Ardiles V, Sanchez Claria R, Pekolj J, de Santibañes E. Associating liver partition and portal vein ligation for staged hepatectomy (ALPPS): Tips and tricks, J Gastrointest Surg. 2013; 17:814-821.

54. Vennarecci G, Laurenzi A, Levi Sandri GB, et al. The ALPPS procedure for hepatocellular carcinoma. EJSO. 2014; 40:982-988.

55. Xiao L, Li JW, Zheng SG. Totally laparoscopic ALPPS in the treatment of cirrhotic hepatocellular carcinoma. Surg Endosc. 2015; 29:2800-2801.

56. Cai X, Peng S, Duan L, Wang Y, Yu H, Li Z. Completely laparoscopic ALPPS using round-the-liver ligation to replace parenchymal transection for a patient with multiple right liver cancers complicated with liver cirrhosis. J Laparoendosc Adv Surg Tech A. 2014; 24:883-886.

57. Park JS, Han HS, Hwang DW, et al. Current status of laparoscopic liver resection in Korea. J Korean Med Sci. 2012; 27:767-771

58. Gagner M, Rheault M, Dubuc J. Laparoscopic partial hepatectomy for liver tumor. Surg Endosc. 1992; 6:97-98.

59. Dulucq JL, Wintringer P, Stabilini C, Berticelli J, Mahajna A. Laparoscopic liver resections: A single center experience. Surg Endosc. 2005; 19:886-891.

60. Laurent A, Cherqui D, Lesurtel M, Brunetti F, Tayar C, Fagniez PL. Laparoscopic liver resection for subcapsular hepatocellular carcinoma complicating chronic liver disease. Arch Surg 2003; 138:763-9.

61. Buell JF, Cherqui D, Geller DA, et al. The international position on laparoscopic liver surgery: The Louisville Statement, 2008. Ann Surg. 2009; 250:825-830.

62. Tzanis D, Shivathirthan N, Laurent A, et al. European experience of laparoscopic major hepatectomy. J Hepatobiliary Pancreat Sci. 2013; 20:120-124.

63. Yoon YS, Han HS, Cho JY, Ahn KS. Total laparoscopic liver resection for hepatocellular carcinoma located in all segments of the liver. Surg Endosc. 2010; 24:1630-1637.

64. Ishizawa T, Gumbs AA, Kokudo N, Gayet B. Laparoscopic segmentectomy of the liver: From segment I to VIII. Ann Surg. 2012; 256:959-964.

65. Cho JY, Han HS, Yoon YS, Shin SH. Experiences of laparoscopic liver resection including lesions in the posterosuperior segments of the liver. Surg Endosc. 2008; 22:2344-2349.

66. Han HS, Cho JY, Yoon YS. Techniques for performing laparoscopic liver resection in various hepatic locations. J Hepatobiliary Pancreat Surg. 2009; 16:427-432.

67. Azagra JS, Goergen M, Gilbart E, Jacobs D. Laparoscopic anatomical (hepatic) left lateral segmentectomy: Technical aspects. Surg Endosc. 1996; 10:758-761.

68. Chang S, Laurent A, Tayar C, Karoui M, Cherqui D. Laparoscopy as a routine approach for left lateral sectionectomy. Br J Surg. 2007; 94:58-63.

69. Buell JF, Cherqui D, Geller DA, O'Rourke N, Iannitti D, Dagher I, Koffron AJ, Thomas M, Gayet B, Han HS, et al. The international position on laparoscopic liver surgery: The Louisville Statement, 2008. Ann Surg. 2009; 250:825830.

70. Tranchart H, Di Giuro G, Lainas P, Pourcher G, Devaquet N, Perlemuter G, Franco D, Dagher I. Laparoscopic liver resection with selective prior vascular control. Am J Surg. 2013; 205:8-14.

71. Xiong JJ, Altaf K, Javed MA, Huang W, Mukherjee R, Mai G, Sutton R, Liu XB, Hu WM. Meta-analysis of 
laparoscopic $v s$ open liver resection for hepatocellular carcinoma. World J Gastroenterol. 2012; 18:6657-6668.

72. Matsumata T, Ikeda Y, Hayashi H, Kamakura T, Taketomi A, Sugimachi K. The association between transfusion and cancer-free survival after curative resection for hepatocellular carcinoma. Cancer. 1993; 72:1866-1871.

73. Yamamoto J, Kosuge T, Takayama T, Shimada K, Yamasaki S, Ozaki H, Yamaguchi N, Mizuno S, Makuuchi M. Perioperative blood transfusion promotes recurrence of hepatocellular carcinoma after hepatectomy. Surgery. 1994; 115:303-309.

74. Katz SC, Shia J, Liau KH, Gonen M, Ruo L, Jarnagin WR, Fong Y, D'Angelica MI, Blumgart LH, Dematteo RP. Operative blood loss independently predicts recurrence and survival after resection of hepatocellular carcinoma. Ann Surg. 2009; 249:617-623.

75. Dagher I, Belli G, Fantini C, Laurent A, Tayar C, Lainas P, Tranchart H, Franco D, Cherqui D. Laparoscopic hepatectomy for hepatocellular carcinoma: A European experience. J Am Coll Surg. 2010; 211:16-23.

76. Yin Z, Fan X, Ye H, Yin D, Wang J. Short- and long-term outcomes after laparoscopic and open hepatectomy for hepatocellular carcinoma: A global systematic review and meta-analysis. Ann Surg Oncol. 2013; 20:1203-1215.

77. Fancellu A, Rosman AS, Sanna V, Nigri GR, Zorcolo L, Pisano M, Melis M. Meta-analysis of trials comparing minimally invasive and open liver resections for hepatocellular carcinoma. J Surg Res. 2011; 171:e33-e45.

78. Zhou YM, Shao WY, Zhao YF, Xu DH, Li B. Metaanalysis of laparoscopic versus open resection for hepatocellular carcinoma. Dig Dis Sci. 2011; 56:19371943.

79. Li N, Wu YR, Wu B, Lu MQ. Surgical and oncologic outcomes following laparoscopic versus open liver resection for hepatocellular carcinoma: A meta-analysis. Hepatol Res. 2012; 42:51-59.

80. Vigano L, Laurent A, Tayar C, Tomatis M, Ponti A, Cherqui D. The learning curve in laparoscopic liver resection: Improved feasibility and reproducibility. Ann Surg. 2009; 250:772-782.

81. Milone L, Daskalaki D, Fernandes E, Damoli I, Giulianotti PC. State of the art in robotic hepatobiliary surgery. World J Surg. 2013; 37:2747-2755.

82. Giulianotti PC, Coratti A, Angelini M, Sbrana F, Cecconi S, Balestracci T, Caravaglios G. Robotics in general surgery: Personal experience in a large community hospital. Arch Surg. 2003; 138:777-784.

83. Cho JY, Han HS, Yoon YS, Shin SH. Feasibility of laparoscopic liver resection for tumors located in the posterosuperior segments of the liver, with a special reference to overcoming current limitations on tumor location. Surgery. 2008; 144:32-38.

84. Casciola L, Patriti A, Ceccarelli G, Bartoli A, Ceribelli C, Spaziani A. Robot-assisted parenchymal-sparing liver surgery including lesions located in the posterosuperior segments. Surg Endosc. 2011; 25:3815-3824.

85. Berber E, Akyildiz HY, Aucejo F, Gunasekaran G, Chalikonda S, Fung J. Robotic liver surgery: Results for 70 resections. Surgery. 2011; 149:29-39.

86. Berber E, Akyildiz HY, Aucejo F, Gunasekaran G, Chalikonda S, Fung J. Robotic versus laparoscopic resection of liver tumours. HPB (Oxford). 2010; 12:583586.

87. Ji WB, Wang HG, Zhao ZM, Duan WD, Lu F, Dong JH. Robotic-assisted laparoscopic anatomic hepatectomy in
China: Initial experience. Ann Surg. 2011; 253:342-348.

88. Lai EC, Yang GP, Tang CN. Robot-assisted laparoscopic liver resection for hepatocellular carcinoma: Short-term outcome. Am J Surg. 2013; 205:697-702.

89. Tsung A, Geller DA, Sukato DC, Sabbaghian S, Tohme S, Steel J, Marsh W, Reddy SK, Bartlett DL. Robotic versus laparoscopic hepatectomy: A matched comparison. Ann Surg. 2014; 259:549-555.

90. Buchs NC, Oldani G, Orci LA, Majno PE, Mentha G, Morel P, Toso C. Current status of robotic liver resection: A systematic review. Expert Rev Anticancer Ther. 2014; $14: 237-246$

91. Giulianotti PC, Sbrana F, Bianco FM, Addeo P. Robotassisted laparoscopic extended right hepatectomy with biliary reconstruction. J Laparoendosc Adv Surg Tech A. 2010; 20:159-163.

92. Simillis C, Constantinides VA, Tekkis PP, Darzi A, Lovegrove R, Jiao L, Antoniou A. Laparoscopic versus open hepatic resections for benign and malignant neoplasms - a meta-analysis. Surgery. 2007; 141:203-211.

93. Lesurtel M, Cherqui D, Laurent A, Tayar C, Fagniez PL. Laparoscopic versus open left lateral hepatic lobectomy: A case-control study. J Am Coll Surg. 2003; 196:236-242.

94. Andres A, Toso C, Moldovan B, Schiffer E, RubbiaBrandt L, Terraz S, Klopfenstein CE, Morel P, Majno $\mathrm{P}$, Mentha G. Complications of elective liver resections in a center with low mortality: A simple score to predict morbidity. Arch Surg. 2011; 146:1246-1252.

95. Topal B, Fieuws S, Aerts R, Vandeweyer H, Penninckx F. Laparoscopic versus open liver resection of hepatic neoplasms: Comparative analysis of short-term results. Surg Endosc. 2008; 22:2208-2213.

96. Nguyen KT, Gamblin TC, Geller DA. World review of laparoscopic liver resection: 2,804 patients. Ann Surg. 2009; 250:831-841.

97. Troisi RI, Patriti A, Montalti R, Casciola L. Robot assistance in liver surgery: A real advantage over a fully laparoscopic approach? Results of a comparative biinstitutional analysis. Int J Med Robot. 2013; 9:160-166.

98. Turchetti G, Palla I, Pierotti F, Cuschieri A. Economic evaluation of da Vinci-assisted robotic surgery: A systematic review. Surg Endosc. 2012; 26:598-606.

99. Ho CM, Wakabayashi G, Nitta H, Ito N, Hasegawa Y, Takahara T. Systematic review of robotic liver resection. Surg Endosc. 2013; 27:732-739.

100. Ho CM, Wakabayashi G, Nitta H, Ito N, Hasegawa Y, Takahara T. Systematic review of robotic liver resection. Surg Endosc. 2013; 27:732-739.

101. Leung U, Fong Y. Robotic liver surgery. Hepatobiliary Surg Nutr. 2014; 3:288-294.

102. Llovet JM, Schwartz M, Mazzaferro V. Resection and liver transplantation for hepatocellular carcinoma. Semin Liver Dis. 2005; 25:181-200.

103. Mazzaferro V, Llovet JM, Miceli R, et al. Predicting survival after liver transplantation in patients with hepatocellular carcinoma beyond the Milan criteria: A retrospective, exploratory analysis. Lancet Oncol. 2009; 10:35-43.

104. Fan ST, Lo CM, Liu CL, Lam CM, Yuen WK, Yeung C, Wong J. Hepatectomy for hepatocellular carcinoma: Toward zero hospital deaths. Ann Surg. 1999; 229:322330.

105. Fong Y, Sun RL, Jarnagin W, Blumgart LH. An analysis of 412 cases of hepatocellular carcinoma at a Western center. Ann Surg. 1999; 229:790-779. 
106. Livraghi T, Meloni F, Di Stasi M, Rolle E, Solbiati L, Tinelli C, Rossi S. Sustained complete response and complications rates after radiofrequency ablation of very early hepatocellular carcinoma in cirrhosis: Is resection still the treatment of choice? Hepatology. 2008; 47:82-89.

107. Ruzzenente A, Guglielmi A, Sandri M, Campagnaro T, Valdegamberi A, Conci S, Bagante F, Turcato G, D'Onofrio M, Iacono C. Surgical resection versus local ablation for HCC on cirrhosis: Results from a propensity case-matched study. J Gastrointest Surg. 2012; 16:301-311; discussion 311.

108. Llovet JM, Brú C, Bruix J. Prognosis of hepatocellular carcinoma: The BCLC staging classification. Semin Liver Dis. 1999; 19:329-338.

109. A new prognostic system for hepatocellular carcinoma: A retrospective study of 435 patients: the Cancer of the Liver Italian Program (CLIP) investigators. Hepatology. 1998; 28:751-755.

110. Leung TW, Tang AM, Zee B, Lau WY, Lai PB, Leung KL, Lau JT, Yu SC, Johnson PJ. Construction of the Chinese University Prognostic Index for hepatocellular carcinoma and comparison with the TNM staging system, the Okuda staging system, and the Cancer of the Liver Italian Program staging system: A study based on 926 patients. Cancer. 2002; 94:1760-1769.

111. Kudo M, Chung H, Osaki Y. Prognostic staging system for hepatocellular carcinoma (CLIP score): Its value and limitations, and a proposal for a new staging system, the Japan Integrated Staging Score (JIS score). J Gastroenterol. 2003; 38:207-215.

112. Chevret S, Trinchet JC, Mathieu D, Rached AA, Beaugrand $\mathrm{M}$, Chastang C. A new prognostic classification for predicting survival in patients with hepatocellular carcinoma. Groupe d'Etude et de Traitement du Carcinome Hépatocellulaire. J Hepatol. 1999; 31:133-141.

113. Tateishi R, Yoshida H, Shiina S, Imamura H, Hasegawa K, Teratani T, Obi S, Sato S, Koike Y, Fujishima T, Makuuchi M, Omata M. Proposal of a new prognostic model for hepatocellular carcinoma: An analysis of 403 patients. Gut. 2005; 54:419-425.

114. European Association For The Study Of The Liver; European Organisation For Research And Treatment Of Cancer. EASL-EORTC clinical practice guidelines: Management of hepatocellular carcinoma. J Hepatol. 2012; 56:908-943.

115. Llovet JM, Bruix J. Systematic review of randomized trials for unresectable hepatocellular carcinoma: Chemoembolization improves survival. Hepatology. 2003; 37:429-442.

116. Raoul JL, Sangro B, Forner A, Mazzaferro V, Piscaglia F, Bolondi L, Lencioni R. Evolving strategies for the management of intermediate-stage hepatocellular carcinoma: Available evidence and expert opinion on the use of transarterial chemoembolization. Cancer Treat Rev. 2011; 37:212-220.

117. Zhong JH, Xiang BD, Gong WF, Ke Y, Mo QG, Ma L, Liu X, Li LQ. Comparison of long-term survival of patients with BCLC stage B hepatocellular carcinoma after liver resection or transarterial chemoembolization. PLoS One. 2013; 8:e68193.

118. Minagawa M, Makuuchi M, Takayama T, Ohtomo $\mathrm{K}$. Selection criteria for hepatectomy in patients with hepatocellular carcinoma and portal vein tumor thrombus. Ann Surg. 2001; 233:379-384.

119. Ng KK, Vauthey JN, Pawlik TM, Lauwers GY, Regimbeau
JM, Belghiti J, Ikai I, Yamaoka Y, Curley SA, Nagorney $\mathrm{DM}, \mathrm{Ng}$ IO, Fan ST, Poon RT. Is hepatic resection for large or multinodular hepatocellular carcinoma justified? Results from a multi-institutional database. Ann Surg Oncol. 2005; 12:364-373.

120. Pawlik TM, Poon RT, Abdalla EK, Ikai I, Nagorney DM, Belghiti J, Kianmanesh R, Ng IO, Curley SA, Yamaoka Y, Lauwers GY, Vauthey JN. Hepatectomy for hepatocellular carcinoma with major portal or hepatic vein invasion: Results of a multicenter study. Surgery. 2005; 137:403410.

121. Ruzzenente A, Capra F, Pachera S, Iacono C, Piccirillo G, Lunardi M, Pistoso S, Valdegamberi A, D'Onofrio $\mathrm{M}$, Guglielmi A. Is liver resection justified in advanced hepatocellular carcinoma? Results of an observational study in 464 patients. J Gastrointest Surg. 2009; 13:13131320.

122. Kim RD, Reed AI, Fujita S, Foley DP, Mekeel KL, Hemming AW. Consensus and controversy in the management of hepatocellular carcinoma. J Am Coll Surg. 2007; 205:108-123.

123. Capussotti L, Ferrero A, Viganò L, Polastri R, Tabone M. Liver resection for HCC with cirrhosis: Surgical perspectives out of EASL/AASLD guidelines. Eur J Surg Oncol. 2009; 35:11-15.

124. Wei S, Hao X, Zhan D, Xiong M, Li K, Chen X, Huang Z. Are surgical indications of Barcelona Clinic Liver Cancer staging classification justified? J Huazhong Univ Sci Technolog Med Sci. 2011; 31:637-641.

125. Chang WT, Kao WY, Chau GY, Su CW, Lei HJ, Wu JC, Hsia CY, Lui WY, King KL, Lee SD. Hepatic resection can provide long-term survival of patients with non-earlystage hepatocellular carcinoma: Extending the indication for resection? Surgery. 2012; 152:809-820.

126. Ishizawa T, Hasegawa K, Aoki T, Takahashi M, Inoue Y, Sano K, Imamura H, Sugawara Y, Kokudo N, Makuuchi M. Neither multiple tumors nor portal hypertension are surgical contraindications for hepatocellular carcinoma. Gastroenterology. 2008; 134:1908-1916.

127. Torzilli G, Donadon M, Marconi M, Palmisano A, Del Fabbro D, Spinelli A, Botea F, Montorsi M. Hepatectomy for stage $B$ and stage $C$ hepatocellular carcinoma in the Barcelona Clinic Liver Cancer classification: Results of a prospective analysis. Arch Surg. 2008; 143:1082-1090.

128. Poon RT, Fan ST, Lo CM, Liu CL, Wong J. Long-term survival and pattern of recurrence after resection of small hepatocellular carcinoma in patients with preserved liver function: Implications for a strategy of salvage transplantation. Ann Surg. 2002; 235:373-382.

129. Huang J, Yan L, Cheng Z, Wu H, Du L, Wang J, Xu Y, Zeng Y. A randomized trial comparing radiofrequency ablation and surgical resection for HCC conforming to the Milan criteria. Ann Surg. 2010; 252:903-912.

130. Ho MC, Huang GT, Tsang YM, Lee PH, Chen DS, Sheu $\mathrm{JC}$, Chen $\mathrm{CH}$. Liver resection improves the survival of patients with multiple hepatocellular carcinomas. Ann Surg Oncol. 2009; 16:848-855.

131. Predictive factors for long term prognosis after partial hepatectomy for patients with hepatocellular carcinoma in Japan. The Liver Cancer Study Group of Japan. Cancer 1994; 74:2772-2780.

132. Kanda M, Tateishi R, Yoshida H, Sato T, Masuzaki R, Ohki T, Imamura J, Goto T, Yoshida H, Hamamura K, Obi S, Kanai F, Shiina S, Omata M. Extrahepatic metastasis of hepatocellular carcinoma: Incidence and risk factors. 
Liver Int. 2008; 28:1256-1263.

133. Llovet JM, Bustamante J, Castells A, Vilana R, Ayuso Mdel C, Sala M, Brú C, Rodés J, Bruix J. Natural history of untreated nonsurgical hepatocellular carcinoma: Rationale for the design and evaluation of therapeutic trials. Hepatology. 1999; 29:62-67.

134. Wang Y, Yuan L, Ge RL, Sun Y, Wei G. Survival benefit of surgical treatment for hepatocellular carcinoma with inferior vena cava/right atrium tumor thrombus: Results of a retrospective cohort study. Ann Surg Oncol. 2013; 20:914-922.

135. Wörns MA, Koch S, Niederle IM, Marquardt JU, NguyenTat M, Gamstätter T, Schuchmann M, Schulze-Bergkamen H, Galle PR, Weinmann A. The impact of patient and tumour baseline characteristics on the overall survival of patients with advanced hepatocellular carcinoma treated with sorafenib. Dig Liver Dis. 2013; 45:408-413.

136. Capussotti L, Muratore A, Massucco P, Ferrero A, Polastri $\mathrm{R}$, Bouzari H. Major liver resections for hepatocellular carcinoma on cirrhosis: Early and long-term outcomes. Liver Transpl. 2004; 10:S64-S68.

137. Chok KS, Cheung TT, Chan SC, Poon RT, Fan ST, Lo CM. Surgical outcomes in hepatocellular carcinoma patients with portal vein tumor thrombosis. World J Surg. 2014; 38:490-496.
138. Wu CC, Hsieh SR, Chen JT, Ho WL, Lin MC, Yeh DC, Liu TJ, P'eng FK. An appraisal of liver and portal vein resection for hepatocellular carcinoma with tumor thrombi extending to portal bifurcation. Arch Surg. 2000; 135:1273-1279.

139. Inoue Y, Hasegawa K, Ishizawa T, Aoki T, Sano K, Beck Y, Imamura H, Sugawara Y, Kokudo N, Makuuchi M. Is there any difference in survival according to the portal tumor thrombectomy method in patients with hepatocellular carcinoma? Surgery. 2009; 145:9-19.

140. Ban D, Shimada K, Yamamoto Y, Nara S, Esaki M, Sakamoto Y, Kosuge T. Efficacy of a hepatectomy and a tumor thrombectomy for hepatocellular carcinoma with tumor thrombus extending to the main portal vein. J Gastrointest Surg. 2009; 13:1921-1928.

141. Poon RT, Cheung TT, Kwok PC, et al. Hong Kong consensus recommendations on the management of hepatocellular carcinoma. Liver Cancer. 2015; 4:51-69.

142. Guglielmi A, Ruzzenente A, Conci S, Valdegamberi A, Vitali M, Bertuzzo F, De Angelis M, Mantovani G, Iacono C. Hepatocellular carcinoma: Surgical perspectives beyond the Barcelona clinic liver cancer recommendations. World J Gastroenterol. 2014; 20:7525-7533.

(Received August 3, 2015; Accepted August 10, 2015) 